\title{
The influences of selected clotting and fibrinolysis factors on survival of patients with kidney tumors - a prospective study
}

\author{
Krzysztof Tupikowski ${ }^{1}$, Urszula Jaobsche-Policht ${ }^{2}$, Jadwiga Bittner², Kuba Ptaszkowski ${ }^{3}$, \\ Agnieszka Halon ${ }^{4,5}$, Romuald Zdrojowy ${ }^{6}$, Rajmund Adamiec ${ }^{2}$, Izabela Gosk-Bierska ${ }^{2}$
} \begin{abstract}
Wroclaw, Poland Wroclaw Medical University, Wroclaw, Poland Wroclaw, Poland

Wroclaw, Poland

Submitted: 4 June 2020

Accepted: 25 October 2020

Arch Med Sci

DOI: https://doi.org/10.5114/aoms/128845

Copyright ( 2021 Termedia \& Banach
\end{abstract}

${ }^{1}$ Subdivision of Urology, Wroclaw Comprehensive Cancer Centre, Wroclaw, Poland 2Department of Angiology, Hypertension and Diabetology, Wroclaw Medical University,

${ }^{3}$ Department of Clinical Biomechanics and Physiotherapy in Motor System Disorders,

${ }^{4}$ Department of Pathomorphology and Oncological Cytology, Wroclaw Medical University,

${ }^{5}$ Department of Pathomorphology, Wroclaw Comprehensive Cancer Centre, Wroclaw, Poland ${ }^{6}$ Department of Urology and Oncological Urology, Wroclaw Medical University,

\begin{abstract}
Introduction: Multiple studies suggest that cancer leads to activation of clotting and fibrinolysis pathways, elevating the risk of thromboembolic events. Kidney cancer is often complicated by clotting disorders. In this study, we hypothesized that preoperative clotting and fibrinolysis parameters are altered in healthy volunteers and kidney tumor patients. We also hypothesized that these differences may be associated with survival in patients who have undergone operations due to kidney tumors.

Material and methods: In this study, 96 patients with kidney tumors and 30 healthy volunteers were recruited at a single university center. All patients were assessed for pre-operative serum concentrations of tissue factor (TF), tissue factor pathway inhibitor (TFPI, total TFPI, full-length TFPI, truncated TFPI), plasmin-antiplasmin complex (PAP), thrombin-antithrombin complex (TAT), von Willebrand factor (vWF), clotting factor XIII A1 (FXIIIA1), D-dimers, and fibrinogen. Additionally, standard peripheral blood morphology was evaluated.

Results: Malignant kidney tumors were diagnosed in 85 of 96 tumor patients. In patients with kidney tumors, there were statistically significantly higher concentrations of fibrinogen, D-dimers, TAT, PAF, TF, TFPI, VWF, FXIIIA1, and leukocyte counts compared to the control group. Statistically significant correlations were found between multiple parameters. This points to significant clotting system alterations. Cox stepwise hazard analysis showed that pre-operative fibrinogen and D-Dimer concentrations were significantly associated with survival.

Conclusions: In patients with kidney tumors, multiple clotting and fibrinolysis parameters are significantly altered. Routine pre-operative measures should include determination of fibrinogen and D-dimer concentrations as these markers aid in prediction of survival probability.
\end{abstract}

Key words: kidney tumor, fibrinogen, D-dimer, tissue factor, clotting factor XIII.

\section{Corresponding author:}

Krzysztof Tupikowski MD, PhD

Subdivision of Urology

Wroclaw Comprehensive

Cancer Centre

Pl. Hirszfelda 12

50-413 Wroclaw, Poland

E-mail:

tupikowski.k@dco.com.pl 


\section{Introduction}

Multiple studies have suggested an allied relationship between clotting pathway activation and thromboembolic events [1-4]. Clotting disorders occur in approximately $60 \%$ of cancer patients and in $95 \%$ of those with stage IV disease. Additionally, the presence of venous thromboembolic disease is considered a negative prognostic factor in these patients [4].

It has been reported that $25-30 \%$ of patients with kidney cancer present primarily with metastatic disease, and from those with localized tumors, up to $50 \%$ will develop metastases during the course of the disease [5]. Despite new treatment methods, the 5 -year survival rate is still low, highlighting the aggressiveness of the disease as well as unsatisfactory systemic treatment efficacy $[6,7]$. Due to these factors, it is critical to predict the disease course and probable therapy response. This can aid in tailoring therapy for patient-specific needs, potentially resulting in increased drug efficacy, especially in the era of tyrosine kinase inhibitors and emerging immunotherapies. Still, 4-10\% of patients with kidney cancer present with renal vein thrombosis, and its development is connected with the presence of kidney tumors $[8,9]$. Past observations saw no correlation between renal vein thrombosis and survival, metastatic development, or disease recurrence in kidney tumor patients $[10,11]$. Currently, the presence of kidney tumor thrombosis in the renal vein or inferior cava vein is generally accepted as a negative prognostic factor. As such, this led to the incorporation of kidney cancer staging system disease management guidelines $[12,13]$. Data regarding clotting and fibrinolysis in kidney tumor patients are scarce, but overclotting is believed to be a negative prognostic factor; therefore, further data are needed [14].

The aims of this study were to first compare selected clotting and fibrinolysis factors in patients who had undergone surgery due to kidney tumors as well as in healthy volunteers. Second, we evaluated these factors for their influence on kidney cancer patient survival.

\section{Material and methods}

In this study, 96 consecutive patients who had undergone surgery at the Department of Urology and Oncologic Urology of the Wroclaw Medical University due to kidney tumors were included. There were 30 healthy volunteers included in the study as controls. All research was financed by a university internal grant (No. ST-875) and a grant for young scientists (No. Pbmn-114). This study was approved by the University Bioethics Committee, and all subjects gave written informed consent.

The primary kidney tumor, diagnosed by ultrasonography, was confirmed by abdominal comput- ed tomography or magnetic resonance imaging. Staging was performed using the 2002 TNM system [15], and kidney cancer grading was determined by use of the Fuhrman system [16]. Blood was collected at 0800 hours by venipuncture of the basilic vein. Basic laboratory testing (blood morphology, INR, fibrinogen concentration, thrombin time, activated partial thromboplastin time, prothrombin index) was performed in a local hospital laboratory.

Tissue factor (TF) was assessed using the Imubind Tissue Factor ELISA Kit No. 846 (American Diagnostica Inc., Stamford); serum tissue factor pathway inhibitor (TFPI): total TFPI, full-length TFPI, truncated TFPI were measured using the Imubind total TFPI ELISA Kit No. 849 (American Diagnostica Inc, Stamford, USA); plasmin-anti-plasmin complex (PAP) was assessed using the Enzygnost PAP micro test (Dade Behring, Marburg, Germany); thrombin-anti-thrombin complex (TAT) was measured by Enzygnost TAT micro (Behring, Behringwerke AG, Marburg, Germany); von Willebrand factor (vWF) using the Asserachrom vWF test (Diagnostica Stago, Glattbrugg, Switzerland); D-dimers were assessed using STA-Liatest D-Di (Diagnostica Stago, Glattbrugg, Switzerland); and XIII A1 clotting factor was measured with the ELISA Kit for human coagulation factor XIIIA1 polypeptide (USCN Life Sciences Inc., Wuhan, China). All kits were used according to the manufacturer's recommendations.

\section{Statistical analysis}

Statistical analysis was performed with Statistica 13 (Tibco, USA). For measurable variables, arithmetic means, medians, standard deviations (SD), and variation ranges (extremes) were calculated. For qualitative variables, the frequency of occurrence in percent (\%) was calculated. All investigated variables were tested using the Shapiro-Wilk test to examine distribution type. Kaplan-Meier curves were calculated for overall survival (OS) analysis, and a log-rank test was used for survival comparison between groups. The Cox proportional hazard test and Cox stepwise tests were used for investigating the influence of these variables on survival. Kaplan-Meier curves were calculated for prognostic factor influence. The observable differences between groups was assessed using Student's $t$-test for independent variables or the Mann-Whitney $U$-test. Relationships between selected variables were calculated using Pearson's correlation coefficient or Spearman's rank test. For all comparisons, significance was set at $p \leq 0.05$.

\section{Results}

There were no significant demographic differences between experimental and control patients (Table I). Patients with kidney tumors had signifi- 
Table I. Demographic comparison of kidney tumor patients and controls and clinical data of experimental group

\begin{tabular}{|c|c|c|c|c|c|c|c|c|c|c|c|}
\hline \multirow[t]{2}{*}{ Factor } & \multicolumn{5}{|c|}{ Experimental group $(n=96)$} & \multicolumn{5}{|c|}{ Control group $(n=30)$} & \multirow[t]{2}{*}{$P$-value } \\
\hline & Mean & Median & Min & Max & SD & Mean & Median & Min & Max & SD & \\
\hline Age & 60.6 & 60 & 21 & 88 & 12 & 58 & 58.5 & 44 & 69 & 7 & $0.14^{\star *}$ \\
\hline $\begin{array}{l}\text { Body } \\
\text { weight [kg] }\end{array}$ & 80.5 & 80 & 49 & 125 & 15.6 & 76.2 & 73 & 55 & 120 & 12.6 & $0.12^{\star *}$ \\
\hline Height $[\mathrm{cm}]$ & 168.1 & 170 & 150 & 188 & 9.5 & 169.8 & 170 & 156 & 183 & 8.8 & $0.06^{\star}$ \\
\hline $\mathrm{BMI}\left[\mathrm{kg} / \mathrm{m}^{2}\right]$ & 28.5 & 27.8 & 20.4 & 43.8 & 4.8 & 26.7 & 26 & 21.5 & 39 & 3.6 & $0.07^{\star \star}$ \\
\hline Sex & \multicolumn{5}{|c|}{$\begin{array}{c}\text { Female }-n=41(43 \%) \\
\text { Male }-n=55(57 \%)\end{array}$} & \multicolumn{5}{|c|}{$\begin{array}{l}\text { Female }-n=15(50 \%) \\
\text { Male }-n=15(50 \%)\end{array}$} & $0.48^{\star \star \star}$ \\
\hline
\end{tabular}

\begin{tabular}{|c|c|}
\hline \multirow[t]{5}{*}{ Histology } & Benign - 11 (12\%) \\
\hline & Malignant - 85 (88\%) \\
\hline & CCRCC - $72(75 \%)$ \\
\hline & PRCC - $10(10.5 \%)$ \\
\hline & Other - $3(2.5 \%)$ \\
\hline \multirow[t]{5}{*}{ Stage } & $0-11(11 \%)$ \\
\hline & $1-44(46 \%)$ \\
\hline & $2-10(10.5 \%)$ \\
\hline & $3-10(10.5 \%)$ \\
\hline & $4-21(22 \%)$ \\
\hline \multirow[t]{3}{*}{ Grade } & 0+unknown - 22 (23\%) \\
\hline & $1+2-61(64 \%)$ \\
\hline & $3+4-13(13 \%)$ \\
\hline
\end{tabular}

${ }^{*}$ t-test, ${ }^{* *}$ Mann-Whitney $U$ test, ${ }^{* * *} \chi^{2}$ test. SD - standard deviation, $B M I$ - body mass index, CCRCC - clear-cell renal cell cancer, $P R C C$ - papillary renal cell cancer.

cantly higher concentrations of TAT, PAP, TF, total TFPI, full TFPI, vWF, FXIIIA1, and a higher leukocyte count than controls (Table II). The platelet count in cancer patients was higher, but the difference was not found to be statistically significant. Tissue factor concentration was sixfold higher in the patients with kidney cancer than in healthy volunteers, while total TFPI, truncated TFPI, and full TFPI were 2.0, 2.5, and 1.4 fold higher, respectively. Correlation analysis presented in Table III showed a positive correlation between the concentration of coagulation factors, platelet count, and fibrinolysis factors. The strongest correlation was noted between total TFPI and truncated and full length TFPI. There was no correlation between subfractions of TFPI and TF. In contrast, TF was positively correlated with FXIII. There was also a positive correlation between fibrinogen concentration and the concentration of D-dimers, PAP, total TFPI, and VWF as well as platelet count. Platelet count positively correlated with D-dimers, fibrinogen, TAT, PAP, and leukocyte count.

In 85 out of 96 tumor patients, kidney cancer was diagnosed by histological methods. The remaining
11 patients had benign disease. During the observation course 22 patients died, 20 due to kidney cancer and two due to non-cancerous causes. None of the benign kidney tumor patients died in the course of observation. There were no incidents of death due to venous thrombotic events. The median survival time was 62.5 months. No deaths were observed in the healthy volunteers.

Utilizing Cox proportional hazards analysis, it was observed in the cancer patient group that pre-operative levels of fibrinogen, corrected calcium, C-reactive protein (CRP), PAP, TFPI full, and VWF and female gender were significantly associated with survival, while other parameters preoperative hemoglobin level, leukocyte count, serum iron, sodium, potassium, creatinine, albumin, aspartate aminotransferase, alanine aminotransferase levels - did not reach statistical significance. In a stepwise Cox analysis, only elevated fibrinogen and D-dimer concentrations were significantly associated with survival ( $p=0.004$ and $p=0.005$, respectively) whereas sex was marginally associated with overall survival $(p=0.062)$.

In Kaplan-Meier analysis, patients with increased fibrinogen levels had worse overall survival than those within normal ranges (53.7 vs. 64.7 months, $p=0.000$, Fig. 1 ), and patients with elevated pre-operative D-dimer concentrations had worse overall survival than those with D-dimers within the normal range (55.7 vs. 64.3 months, $p=0.000$, Fig. 2).

\section{Discussion}

Tissue factor is significantly elevated in tumor patients. It plays a role in induction and enhancement of clotting process and is a necessary cofactor for factor VII activation. A complex of TF/ VIla activates factors IX and $X$, thus initiating a reaction cascade that leads to thrombin generation and clotting [17]. Physiologically TF concentration is low but in response to tissue damage it rises dramatically proportionally to the severity of blood vessel wall damage. Tissue factor is also a marker of elevated thromboembolic readiness 
Krzysztof Tupikowski, Urszula Jaobsche-Policht, Jadwiga Bittner, Kuba Ptaszkowski, Agnieszka Halon, Romuald Zdrojowy, Rajmund Adamiec, Izabela Gosk-Bierska

Table II. Comparison of clotting and fibrinolysis parameters between experimental and control group. $P \leq 0.05$

\begin{tabular}{|c|c|c|c|c|c|c|c|c|c|c|c|}
\hline & \multicolumn{5}{|c|}{ Experimental group $(n=96)$} & \multicolumn{5}{|c|}{ Control group $(n=30)$} & \multirow[t]{2}{*}{$P$-value } \\
\hline & Mean & Median & $\min$ & $\max$ & SD & Mean & Median & $\min$ & $\max$ & SD & \\
\hline Fibrinogen [g/l] & 4.51 & 3.90 & 1.90 & 10.50 & 1.84 & 2.63 & 2.45 & 2.22 & 3.92 & 0.40 & $<0.001$ \\
\hline APTT $[s]$ & 31.01 & 30.05 & 22.60 & 49.00 & 4.23 & 31.90 & 31.50 & 29.00 & 38.00 & 2.29 & 0.08 \\
\hline $\begin{array}{l}\text { Prothrombin } \\
\text { index [\%] }\end{array}$ & 102.37 & 102.85 & 57.80 & 121.60 & 8.38 & 101.43 & 101.00 & 95.00 & 114.00 & 4.49 & 0.24 \\
\hline $\operatorname{PLT}\left[10^{\wedge} 3 / u l\right]$ & 266.31 & 251.00 & 130.00 & 696.00 & 93.19 & 236.87 & 241.00 & 170.00 & 280.00 & 24.85 & 0.21 \\
\hline WBC $\left[10^{\wedge} 3 / \mathrm{ul}\right]$ & 7.26 & 6.86 & 3.53 & 15.00 & 2.07 & 5.29 & 5.00 & 4.10 & 8.90 & 1.05 & $<0.001$ \\
\hline TAT [ug/l] & 4.10 & 2.61 & 0.10 & 42.91 & 5.26 & 1.57 & 1.37 & 0.96 & 3.36 & 0.57 & 0.001 \\
\hline PAP [ug/l] & 445.37 & 386.80 & 64.63 & 1506.22 & 290.46 & 298.20 & 299.50 & 221.00 & 441.00 & 48.60 & 0.02 \\
\hline $\mathrm{TF}[\mathrm{pg} / \mathrm{ml}]$ & 718.95 & 389.71 & 113.81 & 6957.82 & 922.08 & 66.23 & 64.33 & 37.80 & 99.80 & 13.74 & $<0.001$ \\
\hline TFPI trunc $[\mathrm{ng} / \mathrm{ml}]$ & 40.16 & 36.50 & 0.00 & 136.81 & 40.18 & 14.37 & 14.69 & 6.28 & 19.66 & 3.38 & 0.15 \\
\hline TFPI total [ng/ml] & 82.56 & 77.18 & 31.79 & 272.71 & 36.48 & 36.84 & 37.77 & 28.40 & 42.92 & 3.74 & $<0.001$ \\
\hline TFPI full [ng/ml] & 39.68 & 31.27 & 10.64 & 156.47 & 27.90 & 23.34 & 22.62 & 15.18 & 38.14 & 5.08 & $<0.001$ \\
\hline vWF [\%] & 140.77 & 137.00 & 60.00 & 372.00 & 51.06 & 84.33 & 84.00 & 47.00 & 112.00 & 15.30 & $<0.001$ \\
\hline FXIII [ng/ml] & 1926.75 & 1455.00 & 629.00 & 7354.00 & 1296.36 & 712.90 & 684.00 & 548.00 & 892.00 & 96.81 & $<0.001$ \\
\hline
\end{tabular}

SD - standard deviation, min - minimum, max - maximum, APTT - activated partial thromboplastin time, INR - international normalized ratio, TT thrombin time, Prot. Index - prothrombin index, PLT - platelets, Hb - hemoglobin, WBC - white blood cells, TAT - thrombin-anti-thrombin complex, PAP - plasmin-anti-plasmin complex, TF-tissue factor, TFPI trunc - serum tissue factor pathway inhibitor truncated, TFPI total - serum tissue factor pathway inhibitor total, TFPI full - serum tissue factor pathway inhibitor full length, vWF - von Willebrand factor, FXIII - factor XIII

$[18,19]$ and is considered an important risk factor for thromboembolic events in cancer patients [20, 21]. It is essential for tumor growth and metastasis formation as it influences angiogenesis. In microparticles of cellular membranes, it is considered the most critical procoagulation factor [22]. Increased TF expression in tumor patients correlates with elevated frequency of thromboembolic events. Tumors with high TF expression cause thromboembolism more frequently than those with low expression of TF [23]. Studies examining the role of TF in kidney tumor patients are scarce. Immunohistochemical analysis has shown localization of TF antigens in the endothelial layer of blood canals inside the tumor, diffuse fibrinogen and factor $V$ presence in perivascular connective tissue, and linear deposits of fibrin along tumor cells. Tissue plasminogen activator was observed in the endothelium of peritumoral vessels. Those results suggest that thrombin is synthesized locally in the tumorous tissue of kidney cancer and a regional fibrinolysis process controls clot formation [24].

In both the physiological and disease states, the prothrombotic activity of TF is inhibited by tissue factor pathway inhibitor (TFPI). Tissue factor pathway inhibitor is a protease inhibitor containing three inhibitory domains. The first domain inhibits the TF/VIla complex, the second domain inhibits factor $\mathrm{Xa}$, and the third domain is responsible for heparin content and lipoprotein binding. Tissue factor pathway inhibitor can primarily bind factor $\mathrm{Xa}$ and the TF/VIIA complex or directly inhibit the TF/VIIa/Xa complex [25]. Several factors modulate TF activity, which affects TFPI concentration, and low TFPI levels correlate with increased risk of venous embolism and recurrence [26-28]. Physiological concentrations of TFPI are not always sufficient to suppress the prothrombotic action of TF [29]. Because of their modes of action, TF and TFPI have become interesting targets of therapeutic intervention in cancer patients due to their ability to lower the risk of thromboembolic events as they can suppress tumor neoangiogenesis, a mechanism necessary for primary tumor and metastasis growth [30]. In this study, we observed significantly elevated levels of TF, total TFPI and full TFPI, while truncated TFPI was elevated but not found to be statistically significant. When compared to healthy volunteers, patients with kidney cancer had elevated TF (6-fold), truncated TFPI (2.5-fold), total TFPI (2-fold), and full TFPI (1.5-fold). Interestingly, there was no correlation between TF and TFPI. It can be presumed that in patients with kidney cancer, TFPI elevation is insufficient to counteract the prothrombotic action of TF. In 


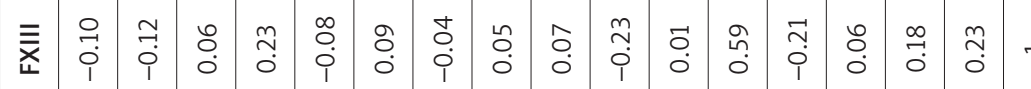

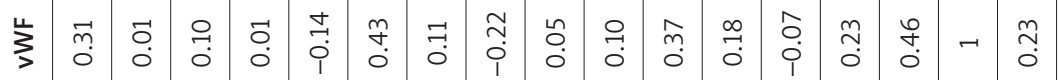

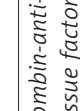





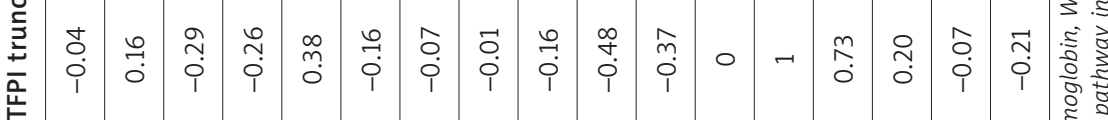

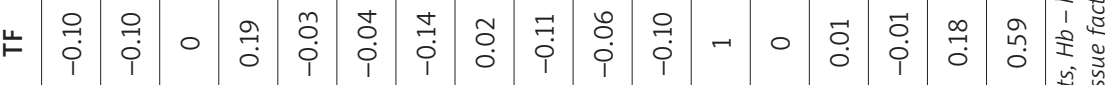

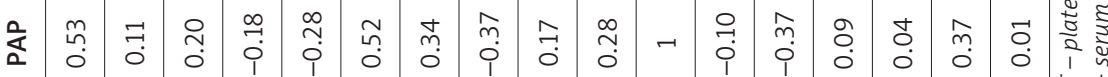

㱏

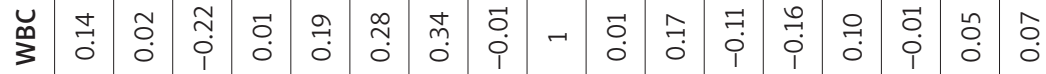



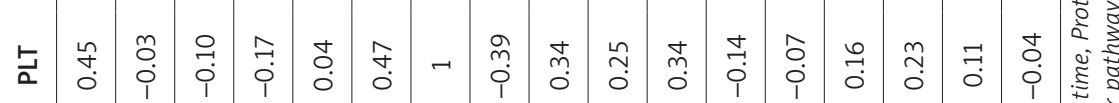



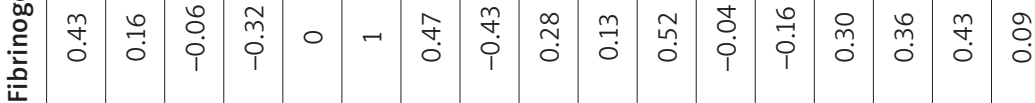

×





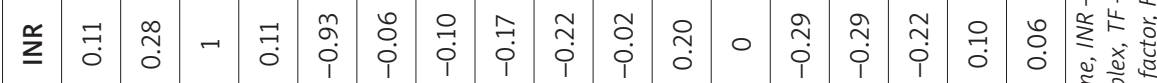

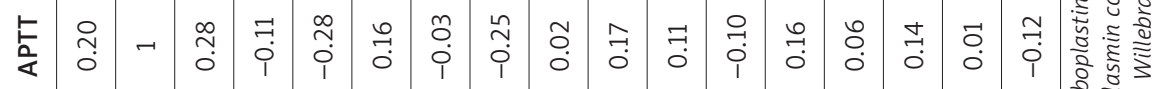



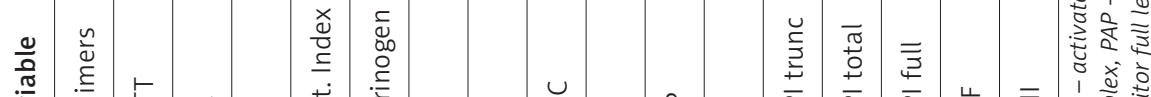

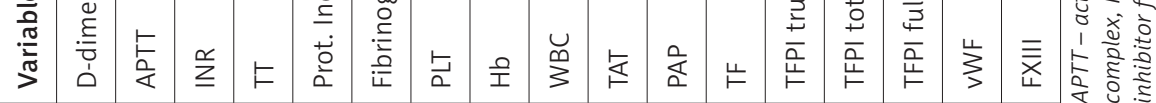


Krzysztof Tupikowski, Urszula Jaobsche-Policht, Jadwiga Bittner, Kuba Ptaszkowski, Agnieszka Halon, Romuald Zdrojowy, Rajmund Adamiec, Izabela Gosk-Bierska

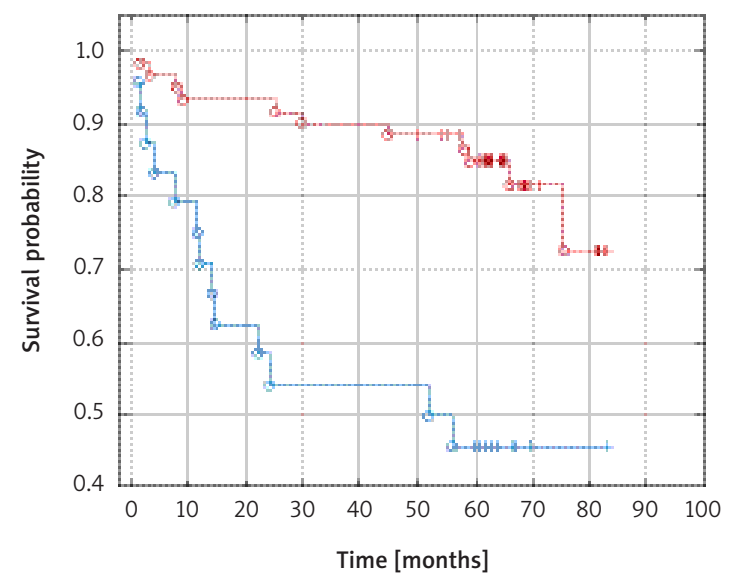

Figure 1. Survival probability (ordinate) in months (abscissa) as related to fibriogen concentration (normal - red, $n=61$, above normal - blue, $n=24$ ) in patients with kidney cancer (53.7 vs. 64.7 months, $p<0.001)$

our study, TF concentrations were only found to correlate with FXIII.

Clotting factor XIII (FXIII) is a zymogen consisting of 2 A catalytic subunits and 2 B carrier subunits (A2B2). In the presence of calcium ions, FXIII is converted by thrombin to active transglutaminase FXIIla by removing $37 \mathrm{~N}$-terminal amino acids of subunit A. Active FXIII stabilizes the clot by forming covalent bonds between fibrin fibers. Substrates for FXIIla are also fibrinolysis inhibitors (alpha 2-PI-inhibitor of alpha 2-plasmin, plasminogen activator inhibitor PAI, thrombin activatable fibrinolysis inhibitor [TAFI]), fibrinogen, adhesive proteins (vitronectin, vitronectin, laminin, vWF factor, thrombospondin), vimentin, plasminogen, and apolipoprotein A [31-34]. Active FXIII also plays a role in the inactivation of the GPIIb-IIla receptor by plasmin; in incorporation of fibrin into the clot, causing thickening of fibrin fibers; and in bond formation between $\alpha_{v} \beta_{3}$ integrin and vascular endothelial growth factor receptor 2 (VEGFR-2) on endothelial cells. Mechanical resistance of the clot, susceptibility to enzymatic fibrinolytic dissolution, resistance to shear forces and to other blood components (urea) are dependent on FXIII [33]. Apart from its role in hemostasis, FXIII acts in the angiogenesis process by forming $\alpha_{v} \beta_{3}$ integrin/ VEGFR-2 bonds on endothelial cells [33, 34]. All these properties support the role of FXIII in matrix formation for primary tumors and metastases. In animal models, it was noted that inhibition of FXIIla action prevents metastasis formation. It was postulated that FXIII takes part in metastasis formation by protecting tumor cells from natural killer (NK) cell action [35]. Additionally, Xu et al. showed different electrophoretic distributions of FXIIIb in patients with kidney cancer as compared to a control group and hypothesized that

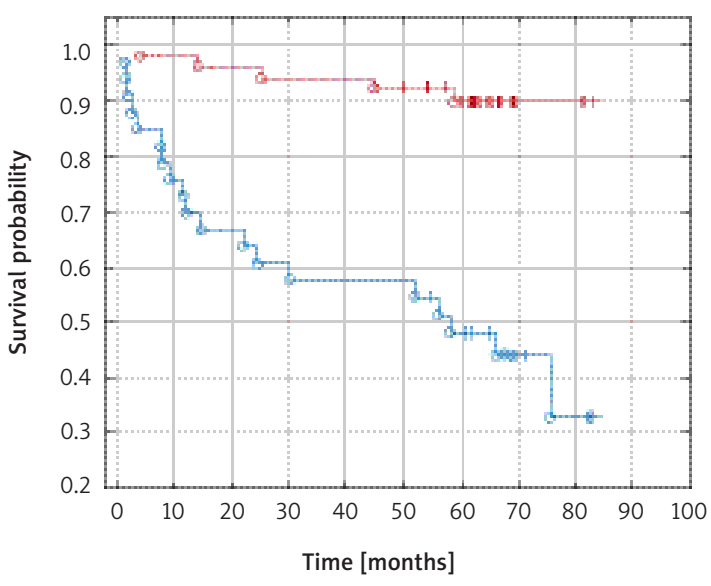

Figure 2. Survival probability (ordinate) in months (abscissa) as related to D-dimer concentration (normal - red, $n=61$, above normal - blue, $n=24$ ) in patients with kidney cancer (55.7 vs. 64.3 months, $p<0.001)$

FXIIIb can be a marker for early kidney cancer [36]. In our study, increased FXIII concentrations were found in kidney tumor patients, suggesting a role for FXIII tumor angiogenesis, particularly as it has a positive correlation with TF concentration.

Our results show that platelet count is important in predicting kidney cancer survival. Both platelet count and function are often aberrant in cancer, and the most common pathology is thrombocytosis. Function aberrations manifest clinically as either bleeding diathesis or thromboembolism. In solid tumors, the tumor cells themselves can induce platelet adhesion and aggregation [37]. Apart from tumor derived microparticles, microplatelets also have TF on the surface and are necessary for thrombin generation [38]. In our study, platelet count was positively associated with clotting activation (TAT), fibrinolysis (D-dimers and PAP), and fibrinogen levels. Fibrinogen is the main ligand for the platelet GPIIb-IIla receptor, which is responsible for platelet aggregation. Platelet counts did not differ in our study between cancer patients and healthy volunteers.

Fibrinogen and D-dimers were significantly correlated with survival in our study. Fibrinogen, apart from fibrin generation in the end phase of the clotting process, is a main ligand for platelet surface receptor GPIIb-IIIa, responsible for aggregation. It is also an acute-phase protein secreted in response to inflammation, infection, trauma, neoplastic processes, acute coronary syndrome, brain ischemia, and venous thromboembolic disease. Fibrinogen concentration is higher in patients with kidney cancer than in patients with benign tumors. Patients with disseminated disease have higher fibrinogen levels than those with localized cancer [39]. Several studies have shown that fibrinogen levels are a prognostic factor for overall 
survival in kidney cancer patients [40-43]. In our study, fibrinogen concentration correlated with endothelial damage (vWF), fibrinolysis activation (PAP, D-dimers), and platelet count. In our study, above normal concentration of fibrinogen (3.5 g/l) significantly lowered the probability of survival in patients with kidney cancer (Fig. 1). Additionally, in patients with kidney cancer, fibrinogen concentration above $5.9 \mathrm{~g} / \mathrm{l}$ was a marker of poor survival.

We also observed a rise in activity of the coagulation system (TAT), fibrinolysis processes (PAP, D-dimers), and elevated endothelial damage markers (VWF, TF) in cancer patients as compared to the control group. D-dimer concentrations above $0.6 \mathrm{mg} / \mathrm{ml}$ were associated with poorer survival in patients with kidney cancer. In patients with combined malignant tumors and D-dimer concentrations above normal (>0.5 mg/dl), lower survival rates were observed when assessed against patients with a normal D-dimer concentration (Fig. 2).

Apart from laboratory abnormalities, the presence of renal vein thrombosis is associated with poor survival. Some authors have observed that renal vein thrombosis does not worsen prognosis in kidney cancer patients $[10,11]$. Others have concluded that the presence of thrombosis and its extent are significant risk factors for poor survival, leading to the TNM staging system: T3a - with thrombus present in the renal vein and $\mathrm{T} 3 \mathrm{~b}$ and $\mathrm{T} 3 \mathrm{C}$ - thrombus present in the inferior cava vein below and above the diaphragm [12, 13].

Our study has some limitations. The experimental group consists of only 96 patients with mixed (malignant and benign) histology. We used this mixed group as pre-operatively we usually do not know the nature of the tumor. Prognostic Cox models were constructed as post-operative models only, but this method tested the influence of clotting and fibrinolysis pathways in cancer patients.

So far, no prognostic model used in clinical decision making incorporates any clotting parameters in patients who undergo surgery due to kidney cancer. The addition of these parameters could increase model accuracy, aid in proper patient selection for surgery, and improve adjuvant treatment options after surgery. They may also provide improved response prediction in patients treated with antiangiogenic or immunomodulatory drugs. Our results support the idea that simple basic laboratory evaluations of fibrinogen and D-dimers prior to surgery could aid in predicting the further disease course and survival of kidney cancer patients.

In conclusion, in patients with malignant kidney tumors, pre-operative and post-operative evaluation of fibrinogen and D-dimers should be mandatory. In kidney cancer patients who under- go surgery due to primary tumors, elevated fibrinogen and D-dimer levels are associated with poor overall survival.

\section{Conflict of interest}

The authors declare no conflict of interest.

\section{References}

1. Glassman AB, Jones E. Thrombosis and coagulation abnormalities associated with cancer. Ann Clin Lab Sci 1994; 24: 1-5.

2. Heit JA, Petterson TM, Bailey KR, et al. The influence of tumor site on venous thromboembolism risk among cancer patients: a population-based study. Blood 2004; 104: 2596.

3. Levitan N, Dowlati A, Remick SC, et al. Rates of initial and recurrent thromboembolic disease among patients with malignancy versus those without malignancy: risk analysis using Medicare claims data. Medicine 1999; 78: 285-91.

4. Thodiyil PA, Kakkar AK. Variation in relative risk of venous thromboembolism in different cancers. Thromb Haemost 2002; 87: 1076-7.

5. Krajowy Rejestr Nowotworów. Available at: http://onkologia.org.pl/nowotwory-nerki/ (Accessed: 17.05.2020).

6. Choueiri TK, Motzer RJ. Systemic therapy for metastatic renal-cell carcinoma. N Engl J Med 2017; 376: 354-66.

7. NCCN Clinical Practice Guidelines in Oncology. Kidney cancer V 2.2020 (Accessed: 17.05.2020).

8. Manso M, Pacheco-Figueiredo L, Santos-Silva A, Silva J, Silva C, Cruz F. Renal cell carcinoma with venous thrombus: should surgery be offered when metastasis is present at diagnosis? Urol Int 2018; 101: 387-90.

9. Zisman A, Wieder JA, Pantuck AJ, et al. Renal cell carcinoma with tumor thrombus extension: biology, role of nephrectomy and response to immunotherapy. J Urol 2003; 169: 909-16.

10. Ficarra V, Righetti R, D’Amico A, et al. Renal vein and vena cava involvement does not affect prognosis in patients. Oncology 2001; 61: 10-5.

11. Rabbani F, Hakimian P, Reuter VE, Simmons R, Russo P. Renal vein or inferior vena caval extension in patients with renal cortical tumors: impact of tumor histology. J Urol 2004; 171: 1057-61.

12. Wagner B, Patard JJ, Méjean A, et al. Prognostic value of renal vein and inferior vena cava involvement in renal cell carcinoma. Eur Urol 2009; 55: 452-9.

13. Europen Association of Urology Guidelines. Edn. presented at the EAU Annual Congress Amsterdam 2020. Available at: https://www.urologosdechile.cl/urolchi/wpcontent/uploads/2020/03/EAU-2020.pdf.pdf.pdf.

14. Tsimafeyeu IV, Demidov LV, Madzhuga AV, Somonova OV, Yelizarova AL. Hypercoagulability as a prognostic factor for survival in patients with metastatic renal cell carcinoma. J Exp Clin Cancer Res 2009; 2: 28-30.

15. Sobin LH, Wittekind C. TNM classification of malignant tumors. $6^{\text {th }}$ ed. New York: Wiley-Liss; 2002.

16. Fuhrman SA, Lasky LC, Limas C. Prognostic significance of morphologic parameters in renal cell carcinoma. Am J Surg Pathol 1982; 6: 655-63.

17. Nemerson Y. Tissue factor and hemostasis. Blood 1988; 71: 1-8.

18. Giensen PL, Rauch U, Borhmann B, et al. Blood-borne tissue factor: another view of thrombosis. Proc Natl Acad Sci USA 1999; 96: 2311-5. 
19. Rauch U, Nemerson Y. Circulating tissue factor and thrombosis. Curr Opin Hematol 2000; 7: 273-7.

20. Manly D, Boles J, Mackman N. Role of tissue factor in venous thrombosis. Annu Rev Physiol 2011; 73: 515-25.

21. Zakai NA, Lutsey PL, Folsom AR, Heckbert SR, Cushman MC. Total tissue factor pathway inhibitor and venous thrombosis. The longitudal Investigation of thromoembolism etiology. Thromb Hemost 2010; 104: 207-12.

22. Davila M, Amirkhosaravi A, Coll E, et al. Tissue factorbearing microparticles derived from tumor cells: impact on coagulation ctivation. J Thromb Haemost 2008; 6: 1517-24.

23. White RH, Chew H, Wun T. Targeting patients for anticoagulant prophylaxis trials in patients with cancer. Who is at highest risk? Thromb Res 2007; 120 Suppl 2: 29-40.

24. Wojtukiewicz MZ, Zacharski LR, Memoli VA, et al. Fibrinogen-fibrin transformation in situ in renal cell carcinoma. Anticancer Res 1990; 10: 579-82.

25. Broze GJ, Girard TJ, Novotny WF. Regulation of coagulation by amultivalent Kunitz-type inhibitor. Biochemistry 1990; 29: 7539-46.

26. Dahm A, Vlieg AH, Bendz B, Rosendaal F, Bertina RM, Sandset PM. Low levels of tissue factor pathway inhibitor (TFPI) incerease the risk of venous thrombosis. Blood 2003; 101: 4387-92.

27. Duering C, Kosch A, Langer C, Thedieck S, Nowak-Gott U. Total tissue factor pathway inhibitor is an independent risk factor for symptomatic paediatric venous thromboembolism and stroke. Throm Haemost 2004; 92: 707-12.

28. Hoke M, Kyrle PA, Minar E, et al. Tissue factor pathway inhibitor and the risk of recurrent venous thromboembolism. Thromb Haemost 2005; 94: 787-90.

29. Mast AE, Bronze GJ Jr. Physiological concentrations of tissue factor pathway inhibitor do not inhibit prothrombinase. Blood 1996; 87: 1845-50.

30. Rickles FR, Patierno S, Fernandes PM. Tissue factor, thrombin, and cancer. Chest 2003; 124: 58-68.

31. Inbal A, Dardik R. Role of coagulation factor XIII (FXIII) in angiogenesis and tissue repair. Pathophysiol Haemost Thromb 2006; 35: 162-5.

32. Mc Donagh J, Mc Donagh RP, Delage JM, Wagner RH. Factor XIII in human plasma and platelets. J Clin Invest 1969; 48: 940-6.

33. Muszbek L, Bagoly Z, Bereczky Z, Katona E. The involvement of blood coagulation factor XIII in fibrinolysis and thrombosis. Cardiovasc Hematol Agents Med Chem 2008; 6: 190-205.

34. Schwarz ML, Pizzo SV, Hill RL, McKee PA. Human factor XIII from plasma and platelets. Molecular weights, subunit structures, proteolytic activation, and crosslinking of fibrinogen and fibrin. J Biol Chem 1973; 248: 1359-407.

35. Palumbo JS, Barney KA, Blevis EA et al. Factor XIII transglutaminase support hematogenous tumor cell metastasis through a mechanism dependent on natural killer cell function. J Thromb Haemost 2008; 6: 812-9.

36. Xu G, Hou CR, Jiang HW, et al. Serum protein profiling to identify biomarkers for small renal cell carcinoma. Indian J Biochem Biophys 2010; 47: 211-8.

37. Wojtukiewicz M, Sierko E. Zaburzenia hemostazy u chorych na nowotwory. Onkologia kliniczna. Warsaw: Borgis; 2006. p. 444-76

38. Tilley RE, Holscher T, Belani R, Nivea J, Mackman N. Tissue factor activity is increased in a combined platelet and microparticle sample from cancer patients. Thromb Res 2008; 122: 604-9.

39. Xiao B, Ma LL, Zhang SD, et al. Correlation between Coagulation function, tumor stage and metastasis in pa- tients with renal cell carcinoma: a retrospective study. Chin Med J (Engl) 2011; 124: 1205-8.

40. Masuda H, Kurita Y, Suzuki A, Kanbayashi T, Suzuki K, Fujita K. Prognostic factors for renal cell carcinoma: a multivariate analysis of 320 cases. Int J Urol 1997; 4 247-53.

41. Sasaki T, Onishi T. Pretherapeutic plasma fibrinogen level is an independent survival predictor in renal cell carcinoma. Oncol Res Treat 2015; 38: 374-8.

42. Erdem S, Amasyali AS, Aytac O, Onem K, Issever $\mathrm{H}$, Sanli O. Increased preoperative levels of plasma fibrinogen and D dimer in patients with renal cell carcinoma is associated with poor survival and adverse tumor characteristics. Urol Oncol 2014; 32: 1031-40.

43. Lee H, Lee SE, Byun SS, Kim HH, Kwak C, Hong SK. Preoperative plasma fibrinogen level as a significant prognostic factor in patients with localized renal cell carcinoma after surgical treatment. Medicine (Baltimore) 2016; 95: e2626. 